\title{
PROFESSOR PESQUISADOR: O CASO ROSA
}

\section{Researcher-teacher: the case of Rosa}

\author{
Alberto Villani ${ }^{1}$ \\ Denise de Freitas ${ }^{2}$ \\ Rosa Brasilis ${ }^{3}$
}

Resumo: Este trabalho aborda o caso de uma professora de Biologia do Ensino Médio que teve, como foco de investigação, sua própria prática docente, e analisa as condições que permitiram o acoplamento da pesquisa com a docência. A prática da professora foi registrada com gravações audiovisuais e com a elaboração de um diário de bordo pessoal. As leituras dos registros, referenciadas nos princípios do contrato didático e nos pressupostos do diagnóstico pedagógico, revelam-nos algumas das ações e reações da professora e dos alunos em momentos de sua prática pedagógica. Os desenvolvimentos da pesquisa e da docência puderam avançar de maneira colaborativa graças ao esforço e à vontade persistente da pesquisadora em utilizar uma metodologia de pesquisa capaz de incorporar tanto aspectos objetivos quanto subjetivos referentes à prática docente.

Palavras-chave: Professor-pesquisador. Subjetividade. Metodologia de pesquisa.

\begin{abstract}
This work presents the case of a high school Biology teacher that had as investigative focus her own educational practice and analyzed the terms that allowed the research to be joined to teaching. The teacher 's practice was collected with audiovisual recordings and a personal logbook. The research and teaching developments could advance thanks to the effort and persistent of the researcher in using the research methodology,was also able to incorporate objective aspects as well as subjective ones with regard to educational practice.
\end{abstract}

Keywords: Teacher-researcher. Subjectivity. Research methodology.

\footnotetext{
${ }^{1}$ Licenciado em Filosofia, Doutor em Física; Docente, Instituto de Física, Universidade de São Paulo. São Paulo, SP, Brasil. Auxílio parcial do CNPq. avillani@usp.br

${ }^{2}$ Licenciada em Biologia, Doutora em Educação; Docente, Deptartamento de Metodologia de Ensino, Universidade Federal de São Carlos. São Carlos, SP, Brasil. Auxílio parcial do CNPq. dfreitas@ufscar.br

${ }^{3}$ Licenciada em Biologia, Mestre em Educação. Nome e instituição fictícios, pois por razões pessoais a professora preferiu manter o anonimato. Como sua participação no trabalho foi fundamental, a autoria poderá ser recuperada identificando-se como Rosa Brasilis. ${ }^{1}$ Avenida Conselheiro Rodrigues Alves, 737
São Paulo, SP
04.014-012 


\section{Introdução}

O movimento de aproximação entre trabalho docente e pesquisa partiu dos estudos de Dewey, que, no início do século XX, nos EUA, diferenciou o ato reflexivo do professor e suas tomadas de decisões rotineiras e sugeriu que um educador competente deveria acompanhar sua prática com uma reflexão sistemática. Dewey influenciou profundamente a educação em seu país até o lançamento do Sputnik em 1957, época na qual suas ideias sobre a formação do 'homem completo' foram drasticamente reduzidas aos aspectos técnicos para tentar atingir a mesma eficácia das escolas russas.

$\mathrm{Na}$ década de 1970, as ideias sustentadas por Stenhouse na Inglaterra tiveram um papel significativo em relação à emancipação do professor para a superação do paternalismo e da dependência: com esse autor, a pesquisa apareceu pela primeira vez como suporte da autonomia do professor, focalizando, sobretudo, o currículo, ou seja, o processo de transmissão do conhecimento em sala de aula (STENHOUSE, 1975). Na década de 1980, Schön (1983) retomou as propostas de Dewey e sugeriu uma maneira nova de o professor desempenhar seu papel: enfrentando, de maneira pessoal, a multiplicidade de desafios na medida em que estes se apresentassem, e refletindo continuamente sobre suas estratégias, reelaborando-as quando oportuno. Ele especifica em que consistiria a reflexão ${ }^{4}$, relacionando-a com a pesquisa a ponto de quase identificar o professor reflexivo com o professor pesquisador.

$\mathrm{Na}$ Europa, Elliot desenvolveu teses parecidas, retomando a herança de Stenhouse, prematuramente falecido em 1982, e ampliando a ideia do professor pesquisador de sua prática docente (ELLIOT, 1986). Mais do que isso, a prática reflexiva, em sua forma metódica e coletiva, tornou-se uma maneira de enfrentar a complexidade crescente da sala de aula, já que o professor aceita fazer parte do problema, tornando a rotina paradoxal, ou seja, sempre recheada de novidades, e construindo suas próprias iniciativas em função do contexto escolar.

A partir dessas propostas, o modelo do Professor Reflexivo e Pesquisador adquiriu uma perspectiva mais ampla com as contribuições de autores como: Nóvoa (1992), que focalizou de maneira sistemática o desenvolvimento pessoal do professor; Zeichner (1993, 1997), que apontou a importância da aceitação, por parte da academia, da pesquisa-ação desenvolvida por professores, e Tardif (2000), que sintetizou e descreveu os saberes profissionais dos professores, qualificando-os como temporais, plurais e heterogêneos, além de personalizados e situados. Em resumo, esse movimento tomou uma multiplicidade de caminhos (ANDRÉ,

\footnotetext{
${ }^{4}$ A reflexão sobre a prática, segundo Schön (2000), pode se dar em diferentes categorias e momentos: i) conbecimento-na-ação, que se manifesta no saber-fazer, na solução de problemas da prática, fruto da experiência e de reflexões anteriores; ii) reflexão-na-ação, que se refere aos processos de pensamento que se realizam durante o desenvolvimento da experiência, tendo como objetivo identificar os problemas que surgem durante a ação e promover mudanças no curso da intervenção; iii) reflexão sobre a ação, que ocorre num momento posterior à intervenção e no intuito de repensar o vivido, descrevendo e objetivando o que já ocorreu; iv) reflexão sobre as reflexões-na-ação, que implica um distanciamento maior da ação e a interpretação e investigação do próprio processo, permitindo uma revisão contínua da prática.
} 
2001); assim, na literatura internacional, destacam-se linhas de trabalho e autores que enfatizam e valorizam: i) a pesquisa colaborativa; ii) o professor como investigador de sua prática no contexto de reformas curriculares; iii) a investigação-ação como espiral de reflexão para melhorar a prática, no sentido emancipatório, e; iv) a autorreflexão coletiva no ambiente escolar.

No Brasil, esse movimento adquiriu voz de várias maneiras: i) a consideração da pesquisa como princípio científico e educativo; ii) a combinação de pesquisa e prática no trabalho e formação de professores; iii) a discussão do papel didático que pode ter a pesquisa na articulação entre saber e prática docente, e iv) a ênfase na importância da pesquisa como instrumento de reflexão coletiva sobre a prática. Algumas pesquisas indicam que o ponto mais forte de investigações realizadas por professores/as está na relevância, pois as questões se relacionam a problemas da sala de aula e da prática escolar. Porém, alguns trabalhos apresentam deficiências metodológicas significativas e, ainda, encontram-se poucas evidências para se sustentarem os resultados apresentados. Enfim, há controvérsias quanto à formação e ao trabalho do/a professor/a como investigador/a. Alguns advogam que as atividades de ensino exigem habilidades distintas da atividade de pesquisar e que, por isso, a formação de professores/as e de pesquisadores/as deve estar voltada para o desenvolvimento de competências exigidas para cada uma das suas funções. Entretanto, outros chamam a atenção para a contribuição que a pesquisa sobre sua própria prática docente traz para o aperfeiçoamento da mesma e da docência em geral (por exemplo, PONTE e BOAVIDA , 2004).

Ludke (2001) sugere que a participação de professores em pesquisas em andamento pode prepará-los para realizar suas próprias pesquisas. Além disso, aponta que é fundamental que os professores tenham uma formação teórica que possa muni-los de elementos para trabalharem os dados que têm em mãos e interpretarem de forma complexa o problema que tentam solucionar. A teoria também ajuda a estabelecer uma distância com o objeto de estudo e, junto com a metodologia de pesquisa, permite um avanço do conhecimento sobre esse objeto. A mesma autora coordenou um número da revista "Cadernos de Pesquisa" (LUDKE, 2005) dedicado ao tema "pesquisa e formação docente", com artigos de pesquisadores de renome, como Tardif e Zeichner, mostrando a atualidade desse debate. Escreve a coordenadora:

A prática da pesquisa pelo professor de educação básica é cercada de dificuldades, especialmente na rede pública... E o reconhecimento da pesquisa feita por ele é objeto de discussões e controvérsias, embora já tenha conquistado um bom número de defensores... ajudando a distinguir aspectos importantes e secundários, na busca de assegurar os ganhos que podem advir do esforço de pesquisa do professor, sem desconsiderar as exigências dirigidas a todos os trabalhos de pesquisa. (LUDKE, 2005, p. 3)

Mais recentemente, a autora coordenou um trabalho "sobre a pesquisa realizada por professores da educação básica e como ela é considerada por pesquisadores experientes da universidade" (LUDKE, 2009, contracapa). Apesar de não conseguir destes uma resposta consensual sobre o que conta efetivamente como pesquisa, a pesquisa consegue delinear "caminhos mais promissores para o trabalho de pesquisa em educação de todos os professores, de qualquer nível de ensino" ( LUDKE, 2009, contracapa). Em síntese, o debate sobre as possibilidades de o professor do Ensino Básico tornar-se pesquisador aponta dois problemas diferen- 
tes, apesar de relacionados: a) conseguir deslocar o foco da reflexão do professor do sucesso imediato de suas iniciativas para um entendimento mais geral das condições de possibilidade de sua docência; b) conseguir manter esse novo olhar nas condições desfavoráveis do ensino público brasileiro. Consequentemente, tem sido apontada a necessidade tanto de uma situação formativa específica que inicie o professor na pesquisa quanto de algum tipo de mudança institucionalizada na condição docente, como, por exemplo, um tempo oficialmente garantido para a pesquisa e/ou uma colaboração sistemática com pesquisadores da universidade.

Uma situação bastante favorável para auxiliar o professor a entrar no mundo da pesquisa tem sido sua participação em cursos de pós-graduação, especialmente de mestrado, sobretudo pela necessidade de elaborar uma dissertação baseada numa pesquisa avaliada com critérios bastante rigorosos. De fato, vários trabalhos de professores do Ensino Básico realizados nessa condição têm sido apresentados em congressos como ANPED, ENDIPE, EPEF, ENPEC, SNEF. Isso sugere como bastante promissor analisar casos específicos de pesquisas conduzidas por professores a fim de localizar as dificuldades encontradas e as condições que auxiliaram a superá-las. Espera-se assim obterem-se informações que sejam relevantes para facilitar a formação de futuros professores-pesquisadores no contexto da pós-graduação ou em situações nas quais a atuação do professor possa ser simultaneamente reflexiva e investigativa.

Neste trabalho, analisaremos o caso de uma professora do Ensino Médio (Rosa) que realizou seu trabalho de mestrado investigando sua própria prática docente. O relato salientará tanto os momentos nos quais pesquisa e docência puderam avançar de forma colaborativa quanto os momentos de impasse nos quais os resultados estavam aquém das expectativas. Nosso interesse principal será: focalizar os elementos subjetivos e objetivos que contribuíram para o processo de acoplamento de elementos de pesquisa sobre o fazer docente.

\section{A metodologia de pesquisa}

O objeto deste trabalho é a análise e interpretação da experiência de Rosa como pesquisadora num curso de pós-graduação e como professora de Biologia numa escola pública numa cidade do Estado de São Paulo.

Em particular, serão empregados os seguintes recursos e ferramentas metodológicas:

1) trechos de gravações audiovisuais das aulas,

2) diário de bordo da professora registrando suas reflexões sobre a ação;

3) anotações e registros sobre os encontros com grupos de interlocutores/as. Os encontros envolveram um grupo da universidade e uma professora da escola.

A narração, iniciada com a entrada em campo da professora, será dividida em partes de modo a caracterizar suas fases de atuação e os diferentes tipos de relações estabelecidas com o ensino e a pesquisa. Pretendemos caracterizar as dificuldades por ela encontradas, as escolhas realizadas e, na medida do possível, as razões conscientes ou inconscientes das mesmas.

\section{Os antecedentes}

Ao iniciar sua pesquisa de campo, assumindo algumas aulas de Biologia numa escola estadual na qual pretendia desenvolver seu projeto, Rosa estava inscrita na pós-graduação há um ano, tendo frequentado anteriormente uma disciplina sobre metodologia de pesquisa e 
uma referente à formação de professores, ficando particularmente interessada nas idéias de Schön e Zeichner sobre professor reflexivo. Nessa época, trabalhava também estavelmente como educadora dedicando a essa atividade mais de 20 horas semanais, e tinha decidido cursar disciplinas do programa de pós-graduação, para terminar os créditos de disciplinas. A professora tinha terminado sua licenciatura há quatro anos e, portanto, já tinha tido experiências docentes interessantes, em geral positivas (por exemplo, um envolvimento intenso de seus alunos na produção de vídeos ou na participação em atividades de estudo dirigido), mas também desafiadoras (como desencontros entre as aulas ciências e biologia ministradas por ela e as expectativas de alunos trabalhadores frente ao currículo).

A escola escolhida como campo de atuação apresentava uma estrutura física bastante precária. Alguns corredores que separavam os prédios de salas de aula possuíam paredes danificadas, entremeadas por jardins abandonados. Muitas portas e janelas estavam quebradas e não cumpriam suas funções de separar os ambientes e barrar o som das outras salas de aula. Apesar de ser muito discriminada pela fama de ser violenta e desorganizada, a escola se apresentava como um espaço de possibilidades para essa professora. Em discussões posteriores, ela revelou que esperava poder colaborar com os docentes da escola para introduzir melhorias significativas no ambiente. Seria uma tentativa de produzir uma pesquisa-ação colaborativa, explorando para tanto os primeiros degraus da reflexão, de acordo com Schön: a reflexão na ação e a reflexão sobre a ação. O terceiro passo da reflexão seria desenvolvido, mais tarde, na universidade com a colaboração de quem a orientava.

Diante desse quadro bastante complexo, duas questões parecem relevantes para caracterizar a iniciação à pesquisa de Rosa: por que escolher uma escola tão difícil e por que trabalhar uma agenda tão carregada?

A resposta à primeira pergunta pode ser encontrada na história pessoal de Rosa. Quando jovem, entrou em contato com as obras de Paulo Freire e com o imperativo de trabalhar comunitariamente nos bairros pobres. Durante a graduação, também desenvolveu trabalhos com crianças pobres coletoras de sobras de alimentos nas feiras, permanecendo nela o desejo de orientar sua ação educativa em favor da igualdade de oportunidades. O/A orientador/a, que confiava muito na capacidade e dedicação de Rosa, também concordou com essa escolha, que constituiria uma maneira de ampliar os horizontes da pesquisa acadêmica. Enfim, ambos compartilhavam do desafio de desbravar campos socialmente relevantes.

Quanto à segunda questão, devemos considerar que a professora complementava seu salário com dois empregos como educadora, encontrando-se na necessidade de atender as exigências mínimas do cumprimento de disciplinas do mestrado ao mesmo tempo em que ministrava suas aulas, realidade de carga horária bastante comum entre professores da rede estadual de ensino. Renunciar ao emprego, além dos problemas econômicos, implicaria também não ser solidária com a condição mais comum, caracterizada por uma carga horária bastante ampla e pesada. Além disso, o acúmulo de tarefas exatamente no momento de iniciar uma atividade nova sugere uma espécie de "fuga para frente", no sentido de vencer o medo da novidade enfrentando-a em condições objetivas extremamente precárias. De fato, além de atuar como professora nos moldes pregados por Paulo Freire, ela projetava movimentar o conjunto dos professores numa ação coordenada que mudasse substancialmente a situação da escola, tarefa em geral pouco adequada para uma professora que acabava de ingressar no corpo docente da escola. 
Villani, A.; Freitas, D.; Brasilis, R.

No entanto, tanto ela quanto o/a orientador/a não ignoravam a difícil condição de realização da proposta inicial; assim, resolveram que uma boa maneira de enfrentar o desafio seria contar com a colaboração de outros interlocutores, que não os da escola, para refletir e pesquisar a própria prática.

\section{Rosa Professora}

Assim que a professora escolheu a escola e a sala de aula, no início do ano, pôs-se a pensar no que iria fazer no primeiro dia de aula e a se questionar se deveria ouvir as expectativas de seus/suas alunos/as.

[...] aplico um questionário para conhecer melhor meus alunos? Para saber como concebem a escola? O que esperam dela? Me adiantará isto?... Darei conta de atender estas expectativas? Devo levantá-las mesmo considerando que posso não atendê-las? (Diário, 06 fev.)

As expectativas iniciais dos poucos alunos presentes na primeira aula foram ouvidas pela professora numa "escuta sensível". Pediu que formassem um círculo e contassem um pouco de suas origens, histórias de vida, expectativas em relação à formação escolar e "por que resolveram voltar a estudar". No diário, apontou um diagnóstico sobre o "desejo" dos alunos em relação ao saber escolar:

$$
\begin{aligned}
& \text { ELA - [voltou a estudar] para ensinar os filhos; FLOR. - para trabalhar; } \\
& \text { SOL-para melhorar o currículo; CLAU - adora estudar; ALE - sem estudo não } \\
& \text { vamos a lugar nenhum; para trabalho; } M A R \text { - boje se exige estudo; NEI. - gosta de } \\
& \text { estudar. (Diário, } 07 \text { fev.) }
\end{aligned}
$$

Para facilitar seu trabalho, sobretudo pela proximidade entre a atribuição da classe e o início das aulas, a professora resgatou um plano de ensino elaborado anteriormente, como um ponto de partida para inspirar o trabalho atual. No diário, registrou quais seriam os itens de seu convite para estudar.

\footnotetext{
Apresentação rápida da professora e início da construção do contrato didático:

O que espero desta experiência; minhas expectativas (que en possa contribuir para maior aprendizagem; que seja prazerosa; significativa; interessante; formadora); O que espero dos alunos - participação responsável; compromisso; dedicação; presença nas aulas;

Avaliação - qual o sentido dela. Podemos evitar o esquema antigo de "vou fazer o básico para obter nota" e "vou controlar meus alunos e conseguir respeito pela nota"; serão adotadas diversas estratégias de avaliação de ensino-aprendizagem (debates; relatórios; pesquisas; questionários dissertativos; atividades em grupo e individual [is]);

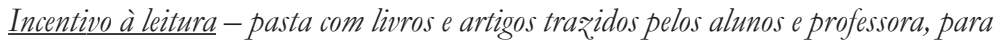
empréstimo. Em aulas serão cedidos momentos de leitura "livre" dos artigos da pasta;
} 
Mestrado-explicar rapidamente, já que falei sobre isso na última aula, aos alunos presentes;

Este contrato é mutável na medida em que amadurecemos nossa relação, na medida em que os alunos trąem sugestões e críticas;

Plano de ensino do semestre (conteúdos gerais), com breves comentários sobre cada temática. (seguindo esquema do livro didático)

Questões:

a) Como se explica uma criança de olhos azuis numa familia com olhos castanhos?

b) Como as características são passadas dos pais para os filhos? (Diário, 08 fev.)

O passo sucessivo da professora foi diagnosticar as concepções dos alunos sobre os conteúdos que seriam abordados. Após a aplicação de exercícios, sistematizou as respostas e ensaiou interpretações que pudessem dar bases para desenvolver tais conteúdos.

[...] estas questões podem não ter permitido a 'soltura' das concepções dos alunos, pois a maioria das duplas respondeu de forma breve e parecida. Terão elas exigido conceitos estritamente escolares, da memória escolar dos alunos? Tenho aplicado estas questões em outras turmas, em anos passados, sem obter melhores resultados. Insisto nelas por não encontrar op̧̧ões melhores. (Diário, 25 fev.)

As respostas dos alunos às questões colocadas geravam um dilema, pois apresentavam, muitas vezes, frases desconexas, diferentes daquelas mais espontâneas que ela esperava. A preocupação expressa no diário parece estar relacionada ao desejo de aplicar questões problematizadoras e que trouxessem à tona e valorizassem as concepções dos alunos, aspecto importante para ela para que ocorresse real aprendizagem.

A professora fez o exercício de interpretar as respostas dos alunos buscando compreender a relação deles com o conhecimento escolar:

[...] De 14 trabalhos (sobre como as características são passadas dos pais para os filhos), 9 duplas falaram sobre células e atribuiram a elas papel na "transmissão de caracteres hereditários" e 7 citaram os grupos sangüineos ou sangue envolvidos neste processo... Vários fatores, integrados, co-relacionados ou não, são citados pelos alunos: células - sangue - força da mente - desejo de que o filho tenha esta on aquela característica - os costumes e cultura são transmitidos pela genética... Também apresentaram cópia de palavras que eu havia há pouco tempo colocado na lousa... percebi que alguns alunos, na tentativa de responder "o que a professora gostaria de ouvir" copiaram palavras da lousa, construindo frases desconexas. (Diário, 25 fev.)

Com as respostas "em mãos" e a constatação de que muitos de seus alunos tinham concepções alternativas sobre células e transmissão de caracteres hereditários, a professora Rosa repensou seus planos, inseriu novos conteúdos na programação do semestre e decidiu iniciar o estudo de genética ligado aos conceitos de células e à temática de reprodução humana. 
[...] o que pensam sobre célula? O que sabem? A que se referem quando atribuem às células o papel de transmissão de caracteres? Trabalho o conteúdo de células com estes alunos? Acho que não terá outro jeito... de que forma retomarei este conteúdo? Pela bistória da produção de conhecimento nesta área? (Diário, 25 fev.)

Como o diagnóstico tinha a finalidade de orientar a professora na busca por atividades didáticas, ela procurou outras opções e formas de trabalhar. Na medida em que dava sequência ao conteúdo a partir do que os alunos indicaram como aprendizagens, ela fez um exercício de analisar as avaliações aluno por aluno, mas pareceu não dar conta de acompanhar a evolução das aprendizagens de cada indivíduo. Nessas condições, a avaliação proporcionava à professora apenas um panorama do quanto foi aprendido a partir do que ela trabalhou em suas aulas.

Durante a aplicação da avaliação individual, uma complexidade de aspectos emergiu da relação dos alunos com a professora (e vice-versa) e destes com o significado de avaliação no processo de ensino e aprendizagem: "[...] estou aplicando a prova - ops, avaliação em sala, individual, frisando o sentido da avaliação, pedindo que não colem, mas está difficil não controlar a cola" (Diário, 09 abr.).

Percebeu a incorporação do modelo de avaliação da escola em suas ações, refletindo sobre a maneira como usualmente o professor insiste na aplicação de provas tradicionais, que deixam os alunos nervosos e incapazes de captar realmente o que aprenderam: "MEU DEUS! Acho que sou exigente mesmo! Muita nota abaixo da média! Vou rever alguns abaixo de 5" (Diário, 09 abr.).

A professora revelou, em vários trechos do diário de bordo, quanto essa tarefa a angustiava. Sentia-se cobrada indiretamente pela instituição escolar a apresentar avaliações mais tradicionais dos alunos, o que a levou a ter de estabelecer um acordo entre os produtos dos alunos, seu desempenho e as regras da instituição.

Em suas ações de ensino subsequentes, percebe-se certo caminho percorrido, muitas vezes sequencial, de enfrentamento do dilema da atribuição de notas. Ela analisava aluno por aluno, anotando suas concepções sobre o conteúdo da avaliação, refletia sobre o que esperava encontrar nas avaliações e experimentava enxergar os alunos não por notas, mas por menções menos taxativas.

Foi dessa forma, também, que a professora foi construindo o diagnóstico pedagógico e percebeu, pela manifestação dos alunos com a manutenção de suas ideias prévias, que a relação deles com o saber científico talvez estivesse num patamar em que aceitavam as justificativas do conhecimento científico, mas não as aplicavam para situações novas. As explicações do conhecimento científico eram apenas memorizadas.

No entanto, esses conflitos não a imobilizaram; pelo contrário, eram motes para avançar em seu planejamento. Utilizou as próprias ideias dos alunos, expressas nas avaliações anteriores, para realizar uma atividade de retomada de conteúdos e ajudar os seus alunos na compreensão dos saberes científicos:

\footnotetext{
ATIVIDADE "VERDADEIRO OU FALSO - POR QUÊ?"

1. O sangue do corpo da mulher preenche o embrião e passa as características genéticas para a criança $[\ldots]$.

2. As características genéticas são passadas para a próxima geração somente através do espermatozóide [...] 


\section{O óvulo é formado por uma única célula [...] (Arquivo pessoal, 16 abr.)}

Ao mesmo tempo em que refletia buscando entender, em contextos mais amplos, não somente os aspectos cognitivos, mas também emocionais dos seus alunos, a meta ainda era encontrar novas saídas de ensino partindo do diagnóstico que ia elaborando sobre as características deles.

[...] - a avaliação não pode ser focada na "prova individual sem consulta" pois os alunos são mais do que mostram nestes momentos;

- alunos e seus problemas - relataram cansaço, sono, faltas devido a trabalho, depressão; - quem são meus alunos? De onde vieram? O que esperam? Devo abandonar o conteúdo de genética e trabalhar DST, sexo, corpo bumano?

- como problematizo o conteúdo de genética? E mais que isso, como trabalho a realidade dos meus alunos? (Diário, 30 abr.)

Aplicou diversos formatos de avaliação - em dupla, lendo e interpretando textos, elaborando questões - e também propôs uma autoavaliação tanto para ela como para os alunos. As respostas foram lidas uma a uma e agrupadas pela professora, fazendo um movimento de escuta concreta. Os alunos puderam expressar seus descontentamentos com o processo, mas, ao mesmo tempo, se comprometeram a participar dele e começaram a aprender a criticar de forma responsável a disciplina de Biologia, além de atentarem para o próprio desempenho. O processo parecia correr em dois trilhos diferentes: o relacionamento com os alunos tornava-se mais familiar e agradável, porém a aprendizagem não parecia avançar a contento. Ao final do semestre escreveu no diário: "Praticamente todos responderam a questão: "como são passadas as características das gerações paternas para as gerações filhas?” da mesma forma que no início do semestre!!! Responderam: através do sangue; de células..." (Diário, 02 jul.).

Em resumo, durante o primeiro semestre, Rosa buscou estabelecer uma relação proveitosa com os alunos e ir ao encontro de suas dificuldades de aprendizagem; o projeto de intervir na escola e promover um trabalho de cooperação com os outros professores ainda era um ideal a ser perseguido. Quanto ao projeto de pesquisa, conseguiu manter a redação de seu diário de bordo e contar com a colaboração de Tabi, pedagoga e mestranda em Educação.

Escrever no diário se constituía num momento em que a professora parava para registrar o ocorrido na escola, fazer teorizações, tecer e rever seus planos de ensino. Questionava-se a partir de algumas ponderações de Zeichner (1993): Por que faz̧ia o que fazia? Com que intenções? Quais foram os resultados? E para quem? Tabi frequentou as aulas de Rosa como observadora desde o primeiro semestre para conhecer os alunos e fazer contatos para futuras entrevistas, referentes a seu trabalho de mestrado. Rosa pediu a Tabi que, se possível, compartilhasse algumas observações das aulas que pudessem colaborar para a reflexão sobre sua prática. Ao serem recebidas, essas anotações provocaram algumas fantasias na professora: “.. recebi de Tabi relatos de seu diário de campo sobre as aulas do semestre passado. Penso: será que minhas aulas eram boas? O que Tabi achava delas? Eu ouvia meus alunos/as? Dava espaço para participação? Ela não far, para meu alivio, julgamentos sobre como eu dava aula...”(Diário, 03 set.).

Um dos dilemas vividos por Rosa neste momento era encontrar um equilíbrio entre as possibilidades da sua "prática efetiva" em sala de aula e seu "ideal de professora", construí- 
do a partir das leituras na pós-graduação e do compromisso social desenvolvido durante sua formação universitária.

\begin{abstract}
"Como problematizo o conteúdo de genética? E mais que isto, como trabalho a realidade de meus alunos? Paulo Freire me faz ver que ainda não considero a realidade de meus alunos. Não desenvolvo uma educação libertadora - "que prepara os alunos para o desvelamento crítico da realidade." Isto muito me incomoda. Como posso considerar a realidade de meus alunos no currículo de Biologia? Como trabalhar a ambientalização da escola? Mudar o ambiente escolar?" (Diário, 30 abr.)
\end{abstract}

\title{
III. Rosa professora e pesquisadora
}

No segundo semestre, a situação de Rosa como pesquisadora avançou em vários aspectos e ela conseguiu estabelecer um diálogo entre sua atuação como professora e sua reflexão como pesquisadora.

Um grande subsídio veio ao entrar em contato novamente com um referencial teórico (VILLANI e CABRAL, 1997), referente à condução e sustentação do processo de ensino e aprendizagem, que ela tinha estudado de maneira superficial numa das disciplinas de pós-graduação. O ponto fundamental que tocou Rosa foi reconhecer que suas anotações no diário de bordo podiam ser facilmente interpretadas mediante esse referencial, que focalizava a dimensão subjetiva das interações entre professora e alunos. De fato, os autores do trabalho apontam que é essencial para o professor: a) estabelecer um contrato de trabalho, constituído dos compromissos assumidos por alunos e professor; b) incentivar a problematização das tarefas a serem realizadas para envolver o aluno num processo de aprendizagem, mantendo-o engajado; c) promover a transferência pedagógica de forma a estabelecer uma relação de confiança recíproca entre professor e alunos, a partir da qual se possa realizar a condução e sustentação dos alunos durante o processo de aprendizagem; d) finalmente, elaborar um diagnóstico pedagógico dos alunos levantando os traços característicos que influenciam suas tendências ou resistências às mudanças. A influência desse esquema apareceu nas reflexões posteriores.

Rosa também encontrou suporte na literatura para enfrentar as dificuldades de realizar mudanças efetivas no âmbito da avaliação: "A COIS A MAIS DIFÍCIL DE MUDAR, DE INOVAR, É A AVALIAÇÃO! Ainda pergunto quem merece nota ou não - quando leio as avaliações dos alunos. Li, com Gil Pereze e Ana Carvalho (2000), que é importante perguntar - como posso ajudar este aluno a evoluir?" (Diário, 06 jul.).

A leitura da teoria sobre avaliação e o clima mais favorável do segundo semestre começaram a ter efeitos na forma como a professora conduziu a "correção" dos trabalhos dos alunos. Estava interessada em perceber se e quanto os alunos conseguiam relacionar o conteúdo científico com sua vida prática e social.

Outro auxílio foi propiciado pela colaboração de uma estagiária para filmar suas aulas: Pabi, graduanda em Física. Também contou com a continuidade da colaboração de Tabi, que, além de observar, filmava as aulas na ausência de Pabi.

Um efeito dessa colaboração foi a volta da reflexão sobre os desejos e expectativas dos alunos. 
[...] A presença de Tabi em minhas aulas me fez.prestar mais atenção nos alunos/as, tentar conbecer estes alunos/as, quem eram eles, de onde vinham, o que pensavam da escola... Provocava-me a considerar mais os alunos/as e seus desejos, seus pensamentos. (Diário, 03 set.)

Com o passar do tempo, a colaboração das duas tornou-se mais sistemática, resultando em encontros de reflexão, que às vezes incluíam outra professora da escola. A espontaneidade e improviso constituíram o procedimento de condução dos encontros, facilitados pela familiaridade entre as três interlocutoras. A aposta da professora centrava-se no poder que o convite do professor pode exercer para que os alunos aceitem aventurar-se na disciplina. Essa aposta fornecia, no caso do contexto de vida de seus alunos do supletivo noturno, um suporte para o desenvolvimento da autoestima. Muitos deles demonstravam não se sentir capazes de aprender. Muitos deles só voltaram a estudar depois de um intervalo grande de tempo, pressionados pela exigência do mercado de trabalho e/ou porque necessitavam ajudar os filhos nas tarefas da escola.

Aprendi que o convite apaixonado e explicito para o processo [de] ensino-aprendizagem deve ser feito pelo professor, diversas vezes na disciplina. Este convite não deixa de ser o do vínculo com parceria professoral alunos para que a aprendizagem ocorra. $O$ vínculo pessoal se dá nas negociações e revisões de compromissos quando os alunos se colocam, explicitando suas dificuldades, por trabalharem [a]] noite, por estarem doentes, com depressão, com filhos doentes, ou seja, colocam-se humanamente, até com fugas, mentiras, disfarces. E eu, como professora, tenho que lidar com estas situações, aprendendo a enxergá-los como bumanos, que possuem uma vida e um círculo de relacõos maior e mais complexo do que a escola, do que [a sua relação] com a disciplina e comigo. (Diário, 22 out.)

Apesar de todo o seu empenho em mudar as estratégias de ensino e de avaliação, a professora percebeu, tomando como referência o diagnóstico pedagógico elaborado em momentos anteriores, que os/as alunos/as ainda encontravam-se no mesmo patamar em relação ao conhecimento científico, ou seja, continuavam com as explicações de suas ideias construídas espontaneamente ou geradas por equívocos de aprendizagem escolar. Porém, dessa vez, o saber da experiência dialogado com o saber curricular e acadêmico de suas interlocutoras Tabi e Pabi permitiu uma reflexão mais racional e um ajuste de sua exigência pessoal e profissional em relação aos avanços da aprendizagem.

O/ a professor/ a tem que aprender a enxergar os pequenos resultados. Tudo é processual, lento e as mudanças e inovações ocorrem no âmbito local, muitas vezes, quase imperceptiveis. O resultado está numa mudança de postura de uma aluna, que pede para sair da sala quando é filmada e depois pede para filmar seus amigos em sala e se oferece para ser parceira da profa. para mostrar uma dinâmica para o resto dos alunos... Está nos alunos pobres que fotografam o rio que foram visitar, mesmo a profa. não pedindo este tipo de registro para o trabalho; está numa leitura extra, de um livro sobre engenharia genética que levei e emprestei para a Rol, depressiva, que dizia não 
entender os comentários de sala de aula; está numa análise mais elaborada de um aluno quando responde uma questão. (Diário, 22 out.).

No mesmo dia, a gravação da aula registrou sua fala com os alunos sobre a avaliação do processo: nesta fala, bastante descontraída, o foco é nas contribuições que a avaliação pode dar para que o conhecimento científico possa ser útil para os alunos na prática e possa ajudálos a pensar de maneira mais elaborada.

Outro auxílio para a pesquisa de Rosa veio dos encontros com um grupo interlocutor, composto por colegas e pelo/a orientador/a, que a ajudavam a separar o que era uma característica ou angústia pessoal do que era um problema da profissão docente. Num total de quatorze pessoas, os/as interlocutores/as participaram das reflexões em encontros previamente agendados, de acordo com a disponibilidade de cada um ou do grupo.

Nos diálogos, ela era levada a fazer o exercício de abstrair seu processo pessoal e desenvolver uma conexão causal com o sistema educacional no qual estava inserida. Por exemplo, os interlocutores chamavam a atenção da professora para aspectos bastante frequentes de sua prática, tais como "puxar questões dos alunos/as" e "não desvalorizar o que os alunos traz̨iam e devolver uma questão maior, abrangendo alguns conteúdos de Biologia". Apontavam também aspectos da prática que podiam ser aprimorados, como, por exemplo, o "exercício de questões", que fazia com os alunos "sem apresentar algo escrito, mas oral"; ainda fazer "perguntas e... identificar os momentos certos para discutir certos assuntos com os alunos/as" (Diário, $02 \mathrm{dez}$ ).

\section{Rosa pesquisadora}

Durante o primeiro semestre do ano seguinte, Rosa resolveu dedicar-se exclusivamente à sua pesquisa para torná-la efetivamente uma dissertação.

Um passo importante foi a sistematização do referencial com o qual interpretava sua prática docente e, particularmente, seu contrato pedagógico. Seu relatório final explicitou isto:

\footnotetext{
A professora enfatiza já no primeiro contato com os alunos suas expectativas em relação à disciplina, ao seu papel e aos papéis esperados do / a aluno/ a como forma de construir o ambiente desejado para o desenvolvimento do processo de ensino e aprendizagem. Ela indica os elementos de participação e responsabilidade sobre esta participação, como fundamentais para o desenvolvimento dos/as alunos/as e da disciplina... A professora também assume um papel de compromisso com seu trabalho quando explicita que deseja que esta disciplina seja significativa para todos/as... A professora também registra no "contrato didático" o seu caráter de flexibilidade - "ele é mutável na medida em que os alunos trazem sugestões e criticas". Contém uma abertura ao incremento e ao abandono de ações, conteúdos, estratégias, etc. no percurso das aulas. Portanto, faz o convite para que os / as alunos / as se impliquem no processo e a ajudem a construir a disciplina e ao mesmo tempo coloca a sua disponibilidade para cumprir os compromissos assumidos. O contrato de trabalho é re-construido em todo o semestre, na medida em que os/as alunos/as respondem, implicita ou explicitamente, aos convites e aos acordos conduzidos pela professora. (Relatório de Pesquisa)
} 
Além disso, suas reflexões sobre o processo de avaliação puderam contar com o questionamento do grupo interlocutor composto por colegas e pelo/a orientador/a. No último encontro com esse grupo, a situação problemática apresentada foi o processo de avaliação dos alunos e os resultados que mostravam poucas aprendizagens.

No bimestre, geralmente, tem umas cinco avaliações, tem em grupo, em dupla, de pesquisa de texto... trabalho de campo, tem outras avaliações que os alunos/ as não ficam na questão da cola. Agora, essa que eu friso de ser individual, escrita e sem consulta, $e$ de ser um trabalho deles. Os alunos ficam desesperados porque relembram muito a prova tradicional e, eu também entro no esquema tradicional porque eu não quero que cole, porque en quero que seja individual mesmo. É ai onde en vejo cada indivíduo. Às vezes, no coletivo, em algumas outras avaliações, a gente não consegue ver o processo de cada um e no individual me dá um pouco mais de subsidios para eu enxergar. Acho que eles ficam nervosos ou tentando responder para acertar o que eles imaginam que é certo e escrevem muito pouco e demonstram muito pouco o conhecimento. É frustrante você ter uma expectativa de aprendizagem e a avaliação mostrar tão pouco. (Diário, $14 \mathrm{abr}$ )

Em seguida, foi questionada sobre "quais conhecimentos esperava encontrar".

$\operatorname{Pr}$ - Que conbecimentos espero encontrar? Eu acho que são vários conhecimentos ou habilidades. Conhecimento específico da Biologia... Se eu estou trabalhando cadeia ou teias alimentares, en quero que ele mostre um conbecimento do conceito de teia ou de cadeia. Ele não precisa colocar uma coisa decorada. É mostrar que ele entendeu ou compreendeu, aprendeu (aí no caso) o conceito geral de teia e de cadeia alimentar. As vezes eu dou na forma de um problema para ele resolver. Ai ele mostra o conceito dele. IS A - Por que essa história de vigiar?

$\mathrm{Pr}-\mathrm{Eu}$ acho muito importante porque eu vejo mais o individuo. Tudo bem que nas outras (avaliações) eu também possa ver, mas nem sempre vejo assim.

$D E$ - Esta aluna que não frequenta as aulas [ver diário], ela não pode ter estudado sozinha?

$\operatorname{Pr}-$ Ela pode, pode ter aprendido em outros lugares.

$D E-M a s$ você acha que ela colou.

$\operatorname{Pr}-$ Acho.

Várias falas - Eu também acho.

DE - Isso já está na nossa docência. E acho que ai a gente recupera Rogers que diz que não existe relação de confiança entre professor e aluno... nós estamos sempre prontos para 'pegar' o aluno de alguma forma.

$\mathrm{Pr}$ - Sem perceber, você se pega usando de poder mesmo, para além da conta. Ai! é complicado ter confiança. (anotações do encontro com os interlocutores, 14 abr.) 
O grupo procurou trazer à tona mais detalhes do que subjazia ao incômodo da professora e, em muitos momentos, estabeleceu-se um processo de identificação dos colegas com o dilema vivido por ela. Essa identificação proporcionou certa relativização do problema apresentado, tratando-o como comum a outras pessoas ou aos docentes em geral, e, ainda, ofereceu sustentação subjetiva e cognitiva para aprofundar as reflexões. Os interlocutores incorporaram, pouco a pouco, novos elementos para a análise da situação e formularam questões bastante provocadoras.

\begin{abstract}
LU - Tem um artigo que trata do dilema de uma professora com alunos/as de segunda série de uma escola de periferia do Rio de Janeiro... que tem todo um contexto de exclusão social bastante acentuado; as crianças não têm a mínima disciplina.... Ela vai falar o seguinte, que o único tipo de avaliação que ela consegue ter que fazer é a do coletivo e de perceber esses indivíduos no coletivo. Então, ela vai saindo do coletivo, e a partir do coletivo, ela consegue perceber mudanças individuais, mas tendo como referência este coletivo. Então eu fico pensando: será que no coletivo não é onde é possivel ver $o$ individual? (anotações do encontro com os interlocutores, 14 abr.)
\end{abstract}

Os interlocutores, com formações e experiências diversificadas, decifravam uma linguagem subentendida na narrativa da professora e a provocavam para lidar com a expectativa de agradar todos os alunos.

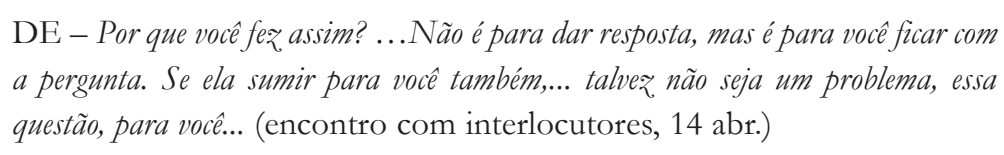

As perguntas permaneceram com Rosa, que avançando em sua reflexão descobriu também que a angústia colocada em seu diário revelava o que não estava presente em suas aulas. O referencial da psicanálise e conversas com outros pesquisadores sugeriram que o problema de boa parte do seu dilema, bastante comum na fase inicial da docência, poderia estar associado à transferência com relação ao Outro, constituído pelo conjunto de autores do campo educacional ao qual normalmente se presta conta, ou seja, sua angústia teria origem fundamentalmente pela confrontação com os modelos ideais de docência e as impossibilidades reais. Essa descoberta, apesar de não significar necessariamente a eliminação do sintoma, ao menos contribuiu para torná-lo menos intenso e enfrentá-lo com mais tranquilidade. Numa apresentação de sua pesquisa, ela comenta:

\footnotetext{
... Essa relação idealizada muitas vezes aprisionava e paralisava [a professora] no processo reflexivo. Acabava se constituindo numa referência importante para a leitura da realidade de seus alunos, porém se transformava em cobrança do que deveria ser feito perante essa realidade. A professora passava a justificar seus atos, intençoes e o 'não cumprimento de transformações da realidade de opressão desses/as alunos/as', no diário, como que respondendo algo a Paulo Freire e a seus princípios pedagógicos. $O$ pensamento de Paulo Freire se tornava, ao mesmo tempo, um norte no campo teórico e um embaraço no campo prático. (Relatório de Pesquisa)
} 


\section{Algumas considerações finais}

Sem dúvida, o trabalho da professora Rosa ao longo de aproximadamente um ano e meio (do início da experiência no supletivo à elaboração escrita de sua pesquisa) constitui um exemplo feliz de acoplamento de docência e pesquisa, tendo como resultado um grande desenvolvimento profissional.

Ela superou algumas ilusões pedagógicas e aumentou sua compreensão quanto à importância de partilhar com o coletivo suas buscas e considerar as estruturas sociais como influenciadoras diretas de sua atuação, ampliando inclusive o significado social da profissão docente. A identificação de dilemas da prática e a escrita autobiográfica possibilitaram também um distanciamento parcial do que fazia e a possibilidade de rever concepções e a atuação como professora. Houve a tomada de consciência do sentido de algumas posturas e condutas profissionais, abrindo caminhos para as tentativas de enfrentamento das contradições vividas. Ao mesmo tempo, aceitou o desafio de defrontar-se consigo mesma e aproximar-se da compreensão do seu próprio processo de pessoa "que aprende", construindo uma empatia com os processos idiossincráticos de seus alunos e facilitando a condução do ensino. Ao focalizarmos as condições que tornaram viável esse processo, podemos considerar os seguintes fatores.

Em primeiro lugar, a grande dedicação e persistência em relação à causa da melhoria do ensino das Ciências. A escolha da docência como profissão fundamental desde o início da graduação em Biologia e o adiamento de sua entrada na pós-graduação, para poder realizar alguns anos de experiência docente, mostram o compromisso que ela tinha com o ensino. Também a escolha de seu tema de pesquisa em seu próprio processo de docência constitui um sinal dessa dedicação, que sustentou o trabalho mesmo quando houve dificuldades significativas. Podemos interpretar que essa motivação para o ensino funcionou, inicialmente, como incentivo para a melhoria das aulas e, ao mesmo tempo, como obstáculo inicial ao envolvimento na reflexão investigativa. Entretanto, nos parece que a dedicação à prática de pesquisa, uma vez iniciada, foi sustentada pela relação de Rosa com o ensinar. Ou seja, nos parece que a pesquisa da professora foi marcada primeiramente pelo desejo de entender e melhorar os fundamentos de seu próprio ensino, mais do que de realizar um trabalho que obtivesse um reconhecimento da comunidade acadêmica e dos pesquisadores na área.

Um segundo elemento extremamente significativo, que constituiu o pivô da experiência, foi a elaboração do diário de bordo, enquanto ocasião de reflexão inicial sobre sua prática e também registro fundamental para a elaboração dos dados da pesquisa e para as discussões com os interlocutores privilegiados. O gosto pela escrita reflexiva de Rosa tinha sido desenvolvido durante a sua formação inicial na disciplina de Prática de Ensino: seu 'caderninho' era constituído não somente de observações sobre a prática, mas de reflexões que revelavam suas escolhas, suas atitudes, suas dificuldades, angústias, alegrias e sofrimentos. O diário de bordo por ela elaborado manteve essa característica de abrigar anotações de fatos e elementos objetivos junto com reflexões sobre sua visão de ensino e de mundo mais geral, além de considerações mais subjetivas sobre sua relação com seu trabalho. Enfim, o diário de Rosa revelou-se uma fonte primordial para a reconstrução de seu processo de envolvimento na pesquisa.

Um terceiro elemento favorável foi a possibilidade de registros mais objetivos sobre sua prática didática, como as gravações em vídeo e as anotações e os comentários dos observadores, que certamente a ajudaram a distanciar-se da prática para enfrentá-la com outro olhar. 
Também a constituição de um grupo de interlocutores na academia, entre colegas e o/a orientador/a, contribuiu com sugestões e novos pontos de vista para a análise das questões apresentadas por Rosa e para a sustentação metodológica da pesquisa. Foi nesses encontros que ela conseguiu desvelar, pelo menos em parte, crenças e atitudes que implicitamente regulavam sua prática didática. O olhar do "outro" estava funcionando como um espelho para a professora.

Finalmente, não podemos deixar de salientar a importância dos referenciais adotados para elaborar e analisar os dados referentes à pesquisa. A caracterização dos vários estágios da reflexão do professor pesquisador orientou a própria articulação entre a prática e a pesquisa. Também foi importante o papel de alguns conceitos da psicanálise para lidar de maneira bastante segura com toda a problemática da subjetividade.

Com relação aos obstáculos e dificuldades encontradas ao longo do projeto, devemos salientar a escassez de tempo disponível para o projeto, o que impactou diretamente a composição de um grupo de interlocutores da escola. Analogamente, devemos citar as dificuldades inerentes à escolha didática realizada: existia um descompasso entre as possibilidades de aprendizagem de alunos adultos que tornavam a estudar após ter abandonado a escola e as metas estabelecidas implicitamente pela professora.

Certas resistências da professora à forma de coleta de dados e à análise de alguns registros de suas aulas estiveram presentes no início do processo e somente quando conseguiu elaborar perguntas específicas sobre sua atuação percebeu que as gravações constituíam fontes importantes de informação que iam além das suas ações para atingir também suas atitudes e, sobretudo, as reações de seus alunos. É importante salientar que, uma vez iniciado, o processo de questionamento da relação de Rosa com o ensino foi além dos elementos visíveis, atingindo vínculos inconscientes: parece-nos que foi essencial, além da disponibilidade de Rosa, o auxílio dos colaboradores e das referências teóricas. No entanto, destacamos aqui que as resistências encontradas por Rosa ao questionamento e ao processo de análise das práticas emergem como uma condição inerente deste tipo de pesquisa e do processo de reflexão sobre a prática, dado que sempre a imagem pessoal e profissional do professor está em jogo.

André (2001) afirma que para a concretização da pesquisa do professor do Ensino Básico é importante garantir que este tenha acesso a condições mínimas, como: i) disposição para investigar e questionar sua prática; ii) formação para aprender a formular problemas e questões investigativas, conhecer e selecionar métodos e instrumentos de observação e de análise; iii) tempo para participar de grupos de estudo em seu local de trabalho; iv) espaço para fazer pesquisa; v) acesso a materiais, fontes de consulta e bibliografia especializada.

Parece evidente que, no caso da pesquisa da professora Rosa, essas condições foram satisfeitas, pelo menos em grande parte. Entretanto, nos parece que a análise desse caso fornece sugestões específicas que vão além das sinalizadas na literatura. De fato, as considerações da literatura constituem uma parte do esforço que o professor e qualquer pesquisador devem realizar se quiser ser incluído no mundo acadêmico. O que o trabalho de Rosa revela é, também, o trunfo que o professor tem ao pesquisar sua própria prática: o acesso às condições implícitas que influenciaram e, às vezes, determinaram essa prática, ou seja, o universo subjetivo do professor. A ausência da referência à relação implícita do professor com os vários tipos de conhecimento (científico, metodológico, curricular e organizacional) torna muito mais precária qualquer análise da prática escolar. Tal acesso é possível somente com a colaboração do professor responsável, retirando-o da condição de apêndice, de elemento não essencial. Isso implica 
tratar os produtos das pesquisas dos professores (que consistem em investigações sobre as próprias práticas) de forma séria na academia, considerando-os como conhecimentos educacionais indispensáveis (ZEICHNER, 1993). Implica também, pelo menos, um comprometimento da academia com o corpo docente em parcerias genuínas, rompendo com os velhos padrões de dominação acadêmica e dando suporte ao desenvolvimento de investigações nas escolas.

\section{Referências}

ANDRÉ, M. Pesquisa, formação e prática docente. In: O papel da pesquisa na formação e na prática dos professores. Campinas: Papirus, 2001. p. 55-69.

ELLIOT, J. La investigación-acción en el aula. Valencia: Generalita Valencia, 1986.

FREITAS, D. Mudança conceitual em sala de aula: uma experiência com a formação inicial de professores. 1998. 215f. Tese (Doutorado em Educação) - Faculdade de Educação, Universidade de São Paulo, São Paulo, 1998.

GIL-PÉREZ, D. ; CARVALHO, A. M. P. Formação de professores de Ciências: tendências e inovações. São Paulo: Cortez, 2000.

LÜDKE, M. A complexa relação entre o professor e a pesquisa. In: ANDRÉ, M. (Org.). O papel da pesquisa na formação e na prática dos professores. Campinas: Papirus, 2001. p. 27-54.

. Pesquisa e formação docente. Cadernos de Pesquisa, São Paulo, v. 35, n.125, p. 11-12, 2005.

(Coord.). O que conta como pesquisa. São Paulo: Cortez, 2009.

NÓVOA, A. Formação de professores e profissão docente. In: . (Org.). Os

professores e a sua formação. Lisboa: Dom Quixote, 1992. p. 15-33.

PONTE, J. P.; BOAVIDA, A. Investigar a nossa prática profissional: o percurso de um grupo de trabalho colaborativo. Educação e Matemática, Lisboa, v. 77, p. 17-20, 2004.

SCHÖN, D. A. The reflective practitioner. New York: Basic Books, 1983.

Educando o profissional reflexivo: um novo design para o ensino e a aprendizagem. Trad. Roberto Cataldo Costa. Porto Alegre: Artes Médicas Sul, 2000.

STENHOUSE, L. An introduction to curriculum research and development. Londres: Heinemann, 1975.

TARDIF, M. Saberes profissionais dos professores e conhecimentos universitários. Revista Brasileira de Educação, São Paulo, v. 13, n. 13, p. 5-24, 2000. 
Villani, A.; Freitas, D.; Brasilis, R.

VILLANI, A.; CABRAL, T. C. B. Mudança conceitual, subjetividade e psicanálise.

Investigações em Ensino de Ciências, Porto Alegre, v. 2, n. 1, p. 43-61, 1997.

ZEICHNER, K. M. A formação reflexiva de professores: idéias e práticas. Lisboa: Educa Professores, 1993.

Tendências Investigativas na Formação de professores. In: ASSOCIAÇÃO

NACIONAL DE PÓS- GRADUAÇÃO E PESQUISA EM EDUCAÇÃO, 20., 1997,

Caxambu. Mesa redonda... Caxambu, 1997.

Artigo recebido em janeiro de 2009 e aceito em novembro de 2009.

496

Ciência \&̊̊ Educação, v. 15, n. 3, p. 479-496, 2009 